\title{
Predictors of in-hospital mortality following mitral or double valve replacement for rheumatic heart disease
}

\author{
Apurba Sharma ${ }^{1}$, Nirmal Panthee ${ }^{2}$, Smriti Mahaju Bajracharya ${ }^{1}$, Bijoy Gopal Rajbanshi ${ }^{2}$, Raamesh Raj \\ Koirala ${ }^{2}$, Jyotindra Sharma ${ }^{2}$, Jeju Nath Pokharel ${ }^{1}$
}

1 Departments of Cardiac Anesthesia, Shahid Gangalal National Heart Center, Bansbari, Nepal
2 Department of Cardiovascular Surgery Shahid Gangalal National Heart Center, Bansbari, Nepal
Corresponding Author Apurba Sharma, Department of Cardiac Anesthesia, Shahid Gangalal National Heart Center
Bansbari, Kathmandu, Nepal, Email: apurbsharma1976@gmail.com, Bansbari, Kathmandu, Nepal, email: medpoonam@gmail.com

Abstract

\begin{abstract}
Backgrounds and Aims: Factors affecting outcome of mitral valve replacement in rheumatic population of Nepal is unknown. The aim of this study was to identify the predictors of in-hospital mortality in patients undergoing mitral or double valve replacement in Nepal.

Methods: A retrospective observational study was designed to evaluate the outcome of patients who underwent mitral valve replacement with or without concomitant other valvular surgery during a period of one year in a tertiary care cardiac centre in Nepal. Data were analysed to find the significant predictors of in-hospital mortality.

Results: A total of 411 patients fulfilled the inclusion criteria. The overall in-hospital mortality was $4.1 \%$ (95\% CI 2.18-6.02). A cutoff value for higher mortality obtained using ROC curve for age was 37.5 years; and for duration of mechanical ventilation was 8.5 hours. Multivariate logistic regression model identified increasing age ( $>37.5$ years), OR 2.05 (95\% CI 0.77-5.45), $\mathrm{p}=0.001$; NYHA Class III and IV, OR 15.18 (95\%CI 0.9-54.53), $\mathrm{p}<0.001$; presence of left atrial thrombus, OR 4.96 (95\% CI 1.49-16.43), $\mathrm{p}=0.003$; tricuspid regurgitation grade III and IV, OR 2.62 (95\% CI 0.95-7.24), p=0.004; re-exploration for bleeding, OR 8.62 (95\% CI 1.60-46.32), $\mathrm{p}=0.03$; left ventricular ejection fraction $(\leq 40 \%)$, OR 8.22 (95\% CI 2.62-25.72), $\mathrm{p}=0.001$; inotrope score $>20$, OR 9.90 (95\% CI 3.48-28.15), $\mathrm{p}<0.001$; duration of mechanical ventilation $>8.5$ hours, OR $22.96(95 \%$ CI $5.15-52.10), \mathrm{p}<0.001$; and stay in the intensive care unit $>2$ days, OR 1.31 (95\% CI 0.49-3.46), $\mathrm{p}<0.001$ as predictors of mortality.

Conclusion: Age, NYHA Class, severe tricuspid regurgitation, presence of left atrial clot, re-exploration for bleeding, decreasing left ventricular ejection fraction, high inotrope score, longer duration of mechanical ventilation, and longer stay in the intensive care unit were identified as the independent predictors of in-hospital mortality.
\end{abstract}

\begin{abstract}
Introduction
Rheumatic valvular heart disease (RVHD) is a condition of global health importance as more than 15 million people are living with the disease. Most of these patients are living in developing countries. The treatment of choice for severe forms of RVHD is surgical correction; either valve repair or replacement. The outcomes following valve replacement differ in different settings and population. The mortality rate and predictors of outcome after rheumatic mitral or double valve replacement in Nepalese population are yet to be explored. The objective of the study was to identify the risk factors for in-hospital mortality after mitral valve replacement in patients with rheumatic mitral valvular heart disease with or without other valvular involvement.
\end{abstract}

\section{Methods}

A retrospective study was designed and institutional review committee's approval was obtained. Data of all patients who underwent elective mitral or double valve replacement with or without other concomitant cardiac surgical procedures from January 2014 to December 2014 was retrieved from the hospital records and analyzed. Patients who underwent emergency mitral valve replacement following complicated percutaneous balloon valvotomy procedures were excluded from the study.

Demographic data including age, gender, and place of residence were assessed from the hospital records. To study whether remoteness of place of living contributes to mortality, the remoteness of the usual place of residence was categorized as non-remote, general remote, remote, and most remote based on the classification by Remote Area Development Committee, Government of Nepal, 1991.

NYHA class, concomitant coronary artery bypass grafting (CABG) and a pre-existing diagnosis of atrial fibrillation were recorded.

The echocardiographic assessment included left ventricular ejection fraction (LVEF), type and number of valves affected, degree of stenosis and regurgitation, left ventricular diastolic and systolic dimensions, dimensions of left ventricular posterior wall, and interventricular septum, and pulmonary artery systolic pressure.

Similarly, cardiopulmonary bypass time, aortic cross clamp time, epicardial pacing requirement, and intraoperative events 
in the form of ventricular arrhythmias after aortic cross clamp release were also recorded.

Outcomes associated with the immediate postoperative results like in-hospital mortality, length of mechanical ventilatory support, inotrope score, re-exploration, renal failure, arrhythmias, and lengths of intensive care stay were also recorded. We calculated inotrope score using the following formula described by Cruz DN et al :

Inotrope score $=($ Dopamine dose $\mathrm{x} 1)+($ Dobutamine dose $\mathrm{x} 1)+($ Adrenalline dose $\mathrm{x}$ 100 $)+($ Noradrenalline dose $\mathrm{x} 100)+$ (Phenylephrine dose $\mathrm{x}$ 100).

\section{Data collection and missing values}

Data collection was done by predefined proforma containing the details of the patient from the hospital records. Missing values were managed either by the deletion of the case if the missing variables were more than $50 \%$ of the total number of variables, or calculating the missing value through averaging or maximum likelihood strategies.

\section{Data analysis and statistical analysis}

Data were analyzed using IBM SPSS Statistics 16 (SPSS Inc, Chicago, IL). Descriptive data were summarized using standard techniques and reported as percentages with $95 \%$ confidence intervals $(95 \% \mathrm{CI})$, means with standard deviation (SD) if the values were evenly distributed or medians with interquartile range (IQR) if the data were non-uniformly distributed.

Comparison between subgroups of survivors and nonsurvivors was undertaken using $\otimes 2$ for categorical data and student's t-test or Mann-Whitney U test for continuous normally distributed or non-normally distributed data respectively. A p value of $<0.05$ was considered statistically significant.

Multivariate linear and logistic models were developed to identify independent factors associated with outcome measures. A backwards stepwise approach was used including in the first model all factors associated with a particular outcome variable using bivariate analysis with a $p$ value $<0.1$. Factors with a $p$ value $\geq 0.05$ were progressively removed from the models starting with those variables with a regression co-efficient closest to 0 .

Final models were limited to predictive factors with significant coefficients $(\mathrm{p}<0.05)$. Cutoff values for the continuous variables identified as independent predictors of mortality were established through Receiver Operating Characteristic (ROC) curves.

\section{Results}

A total of 486 patients underwent valve surgery during the study period. Sixty six patients who underwent isolated aortic valve replacement, five patients with non-rheumatic mitral valve pathology, two patients with severe mitral regurgitation and one patient with pericardial tamponade after percutaneous balloon valvotomy and one patient with missing variables more than $50 \%$ of total number of variables were excluded from the study. Thus, the study sample consisted of 411 patients. Seventeen patients died during the hospital stay resulting in a mortality rate of $4.1 \%$ (95\% CI 2.18-6.02). Demographic and pre-operative characteristics of the patients and results from the bivariate analysis with respect to outcome are detailed in Table 1. Table 1. Demographic and preoperative characteristics of Survivors and Non-survivors

\begin{tabular}{|c|c|c|c|c|}
\hline Variables & Overall $(n=411)$ & Survivors $(\mathrm{n}=394)$ & Non-survivors $(\mathrm{n}=17)$ & $\begin{array}{l}\mathrm{p} \text {-value } \\
\text { (Bivariate analysis) }\end{array}$ \\
\hline Age, years $($ mean $\pm S D)$ & & $32.87 \pm 15.13$ & $45.24 \pm 11.87$ & $<0.001$ \\
\hline Females; n (\%) & $241(58.6)$ & $228(94.6)$ & $13(5.4)$ & 0.12 \\
\hline Males; n (\%) & $170(41.4)$ & $166(97.6)$ & $4(2.4)$ & \\
\hline Address; n (\%) & & & & 0.49 \\
\hline Non-remote & $281(68.4)$ & $272(96.8)$ & $9(3.2)$ & \\
\hline General remote & $81(19.7)$ & $75(92.6)$ & $6(7.4)$ & \\
\hline Remote & $38(9.2)$ & $36(94.7)$ & $2(5.3)$ & \\
\hline Most-remote & $11(2.7)$ & $11(2.8)$ & $0(0)$ & \\
\hline Atrial fibrillation; n (\%) & $284(69.1)$ & $271(95.4)$ & $13(4.6)$ & 0.50 \\
\hline NYHA Class; n (\%) & & & & $<0.001$ \\
\hline NYHA I-II & $119(29.0)$ & $119(100)$ & $0(0)$ & \\
\hline NYHA III & $260(63.3)$ & $254(97.7)$ & $6(2.3)$ & \\
\hline NYHA IV & $32(7.8)$ & $21(65.5)$ & $11(34.4)$ & \\
\hline $\begin{array}{l}\text { Baseline ACT, seconds } \\
(\text { mean } \pm S D)\end{array}$ & $160.11 \pm 47.30$ & $159.20 \pm 47.48$ & $181.12 \pm 28.25$ & 0.06 \\
\hline
\end{tabular}

SD- standard deviation, NYHA- New York Heart Association, ACT- activated clotting time. The percentages of survivors and nonsurvivors are calculated based on outcome of each variable. 
Details of preoperative echocardiographic assessment and results of bivariate analysis are depicted in table 2 .

\section{Table 2. : Echocardiographic parameters}

\begin{tabular}{|c|c|c|c|c|}
\hline Variables & Overall $(n=411)$ & Survivors $(\mathrm{n}=394)$ & Non-survivors $(\mathrm{n}=17)$ & $\begin{array}{l}\text { p-value } \\
\text { (Bivariate analysis) }\end{array}$ \\
\hline $\operatorname{LVID}(\mathrm{d}) ; \mathrm{cm}($ mean $\pm \mathrm{SD})$ & $5.57 \pm 1.22$ & $5.59 \pm 1.20$ & $4.94 \pm 1.50$ & 0.03 \\
\hline $\operatorname{LVID}(\mathrm{s}) ; \mathrm{cm}($ mean $\pm \mathrm{SD})$ & $3.8 \pm 0.99$ & $3.85 \pm 0.97$ & $3.6 \pm 1.27$ & 0.31 \\
\hline LVEF; \% median (IQR) & $60(30-75)$ & $60(30-75)$ & $50(35-64)$ & 0.001 \\
\hline LA size; $\mathrm{cm}($ mean $\pm \mathrm{SD})$ & $5.66 \pm 1.17$ & $5.66 \pm 1.16$ & $5.78 \pm 1.43$ & 0.68 \\
\hline $\begin{array}{l}\text { Presence of LA clot; } \mathrm{n} \\
(\%)\end{array}$ & $27(6.6)$ & $23(85.2)$ & $4(14.8)$ & 0.004 \\
\hline IVS; cm $($ mean $\pm S D)$ & $0.90 \pm 0.17$ & $0.90 \pm 0.15$ & $0.82 \pm 0.16$ & 0.33 \\
\hline $\mathrm{LVPW} ; \mathrm{cm}($ mean $\pm \mathrm{SD})$ & $0.91 \pm 0.17$ & $0.91 \pm 0.17$ & $0.82 \pm 0.16$ & 0.11 \\
\hline MR Grade III-IV; n (\%) & $327(79.5)$ & $315(96.3)$ & $12(3.7)$ & 0.34 \\
\hline MS Grade III-IV; n (\%) & $188(45.7)$ & $177(94.1)$ & $11(5.9)$ & 0.43 \\
\hline AR Grade III-IV; n (\%) & $126(30.6)$ & $125(99.2)$ & $1(0.8)$ & 0.47 \\
\hline AS Grade III-IV; n (\%) & $37(9.0)$ & $37(100)$ & $0(0)$ & 0.17 \\
\hline TR Grade III-IV; n (\%) & $173(42.1)$ & $162(93.6)$ & $11(6.4)$ & 0.004 \\
\hline NYHA IV & $32(7.8)$ & $21(65.5)$ & $11(34.4)$ & \\
\hline $\begin{array}{l}\text { Baseline ACT, seconds } \\
(\text { mean } \pm \text { SD) }\end{array}$ & $160.11 \pm 47.30$ & $159.20 \pm 47.48$ & $181.12 \pm 28.25$ & 0.06 \\
\hline
\end{tabular}

LVID-left ventricular internal diameter (d-diastolic, s-systolic), SD- standard deviation, LVEF- left ventricular ejection fraction, LA- left atrium, cm- centimeter, IVS- inter-ventricular septal dimension, LVPW- left ventricular posterior wall, MR- mitral regurgitation, MS- mitral stenosis, AR- aortic regurgitation, AS- aortic stenosis, TR- tricuspid regurgitation, IQR- interquartile range. The sum of percentages among primary lesion is more than $100 \%$ because of combination of lesions in the same patient. Intraoperative and postoperative variables and results of bivariate analysis are shown in table

Table 3. : Intraoperative and postoperative variables

\begin{tabular}{|c|c|c|c|c|}
\hline Variables & Overall $(n=411)$ & Survivors $(\mathrm{n}=394)$ & Non-survivors $(\mathrm{n}=17)$ & $\begin{array}{l}\text { p-value } \\
\text { (Bivariate analysis) }\end{array}$ \\
\hline Type of surgery & 411 & 394 & 17 & 0.24 \\
\hline Isolated MVR; n (\%) & $148(36.0)$ & $143(96.6)$ & $5(3.4)$ & \\
\hline MVR+TV repair; n (\%) & $117(28.5)$ & $106(90.6)$ & $11(9.4)$ & \\
\hline DVR; n (\%) & $100(24.3)$ & $100(100)$ & $0(0)$ & \\
\hline DVR+TV repair; n (\%) & $45(10.9)$ & $44(97.8)$ & $1(2.2)$ & \\
\hline MVR+CABG; n (\%) & $1(0.2)$ & $1(100)$ & $0(0)$ & \\
\hline Inotrope score; n (\%) & & & & 0.003 \\
\hline$<10$ & $276(67.2)$ & $272(98.6)$ & $4(1.4)$ & \\
\hline $10-20$ & $102(24.8)$ & $96(94.1)$ & $6(5.9)$ & \\
\hline$>20$ & $33(8)$ & $26(78.8)$ & $7(21.2)$ & \\
\hline $\begin{array}{l}\text { CPB time; min } \\
(\text { mean } \pm S D)\end{array}$ & $94.94 \pm 41.05$ & $93.81 \pm 40.92$ & $111.18 \pm 35.14$ & 0.07 \\
\hline $\begin{array}{l}\text { AoX time; min } \\
(\text { mean } \pm S D)\end{array}$ & $76.63 \pm 27.93$ & $66.85 \pm 27.80$ & $75.76 \pm 25.39$ & 0.06 \\
\hline $\begin{array}{l}\text { Reperfusion arrhythmias; } \\
\text { yes; } \mathrm{n}(\%)\end{array}$ & $48(11.7)$ & $45(93.7)$ & $3(6.3)$ & 0.20 \\
\hline $\begin{array}{l}\text { Intraoperative use of } \\
\text { amiodarone; n (\%) }\end{array}$ & $138(33.6)$ & $133(96.4)$ & $5(3.6)$ & 0.71 \\
\hline
\end{tabular}




\begin{tabular}{lllll}
$\begin{array}{l}\text { Epicardial pacing require- } \\
\text { ment; n (\%) }\end{array}$ & $117(28.5)$ & $111(94.9)$ & $6(5.1)$ & 0.52 \\
$\begin{array}{l}\text { Duration of mechanical } \\
\text { ventilation; hours, median } \\
\text { (IQR) }\end{array}$ & $6(1-517)$ & $5(1-312)$ & $48(5-517)$ & $<0.001$ \\
$\begin{array}{l}\text { ICU length of stay; days, } \\
\text { median (IQR) }\end{array}$ & $2(1-75)$ & $2(1-75)$ & $3(1-29)$ & $<0.001$ \\
\hline \begin{tabular}{l} 
Re-exploration; $\mathrm{n}(\%)$ \\
\hline
\end{tabular} & $8(1.9)$ & $6(75.0)$ & $2(25.0)$ & 0.03
\end{tabular}

MVR- mitral valve replacement, TV- tricuspid valve, DVR- double (mitral and aortic) valve replacement, CABG- coronary artery bypass grafting, CPB- cardiopulmonary bypass, AoX- aortic cross clamp, SD- standard deviation, ICU- intensive care unit, IQR-interquartile range

Results of multivariate analysis revealed predictors of in-hospital mortality as shown in table 4.

\begin{tabular}{llll}
\hline \multicolumn{2}{l}{ Table 4. : Results of multivariate analysis identifying predictors of in-hospital mortality } & \\
\hline Variables & Odds ratio & $95 \%$ confidence inter-val & p-value \\
\hline Age (> 37.5 years) & 2.05 & $0.77-5.45$ & .001 \\
\hline NYHA Class (III and IV) & 15.18 & $0.9-54.53$ & $<0.001$ \\
\hline Presence of LA clot & 4.96 & $1.49-16.43$ & .003 \\
\hline Left ventricular ejection fraction ( $\leq 40 \%)$ & 8.22 & $2.62-25.72$ & .001 \\
\hline Tricuspid regurgitation (Grade III and IV) & 2.62 & $0.95-7.24$ & .004 \\
\hline Inotrope score (>20) & 9.90 & $3.48-28.15$ & $<0.001$ \\
\hline $\begin{array}{l}\text { Duration of mechanical ventilation }(>8.5 \\
\text { hours) }\end{array}$ & 22.96 & $5.15-52.10$ & $<0.001$ \\
\hline ICU length of stay (>2 days) & 1.31 & $0.49-3.46$ & $<0.001$ \\
\hline Re-exploration & 8.62 & $1.60-46.32$ & .03
\end{tabular}

NYHA- New York Heart Association, ICU- intensive care unit

Age of the patient and duration of mechanical ventilation had area under the curve of 0.732 and 0.923 , showing significant correlation between them and mortality. A cut off value for increase in mortality was after the age of 37.5 years and duration of mechanical ventilation longer than 8.5 hours.

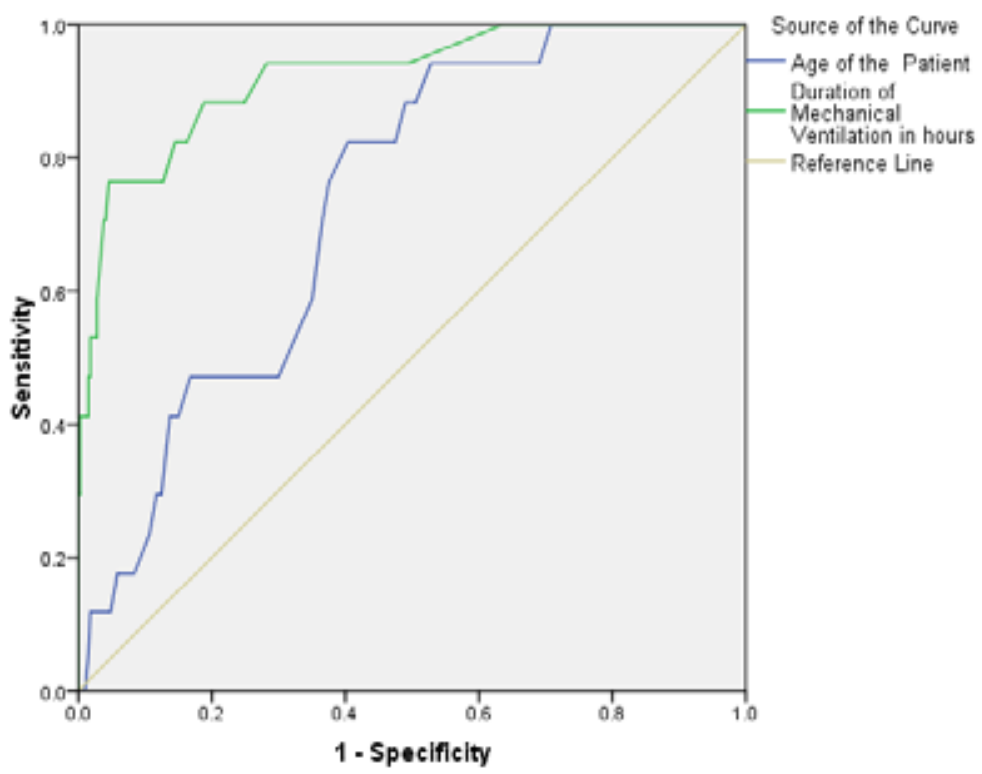

Preoperative and postoperative renal function was excluded from analysis due to high degree of missing values. 


\section{Discussion}

This study is an attempt to identify the predictors of in hospital mortality in RVHD patients undergoing mitral or double valve replacement in Nepal.

Demographic characteristics did not show differences between survivors and non-survivors. More females of reproductive age group presented for valve replacements for RVHD. This is similar to the global trend of $61 \%$ prevalence in females. However, our study population comprised of young patients of productive age group with mean age of 33 years. This signifies the necessity of more aggressive primary prophylaxis for RHD in the country. In the study, large number of patients presented from the non-remote areas; mostly from the districts around the Kathmandu valley. Patients from the most-remote areas comprised only $2.6 \%$ probably because most of the remote and most-remote population still has poor access to cardiac care. Remote location was not a significant predictor of either short or long term outcome in Australia, but remote location of Australia and Nepal differs hugely in terms of affordability and accessibility to health care. Since prevalence of RHD in two of the neighboring countries, India and China, is described as higher; 3 a detailed nationwide population based study is needed to quantify the disease burden in the country. Our study population showed a very high prevalence of atrial fibrillation (AF); almost two thirds (70\%) presenting with $\mathrm{AF}$. The global rheumatic heart disease registry (REMEDY) documented 21.8\% of RHD patients with atrial fibrillation. AF is a late feature of rheumatic heart disease and its incidence increases with age and disease progression, dilatation of left atrium associated with mitral stenosis and regurgitation. This added pre-operative $\mathrm{AF}$ burden limits the choice of prosthesis to mechanical alone with need of anticoagulation and its associated risks. Most of the patients $(71.3 \%)$ had a poor functional class (NYHA III and IV); which signifies late presentation for treatment. Our results emphasize the need for awareness programs in the community for early hospital visit if symptoms of acute rheumatic fever or RHD are seen.

Echocardiographically, mitral regurgitation was seen in almost $80 \%$ of patients. Aortic valve involvement was seen in almost $30 \%$ cases. Left atrial dilatation and clot in the left atrium were other echocardiographic findings. The findings are similar to echocardiographic findings in other rheumatic valve replacement populations., ,

The in-hospital mortality was $4.1 \%$ (95\% CI 2.18-6.02). The overall operative mortality reported by Galloway et al in 1989 was $5.0 \%$ for valve repair, $16.6 \%$ for mechanical MVR, and $10.6 \%$ for porcine MVR. Ho HT et al reported 30 day mortality rate of $0.7 \%$ in Vietnam over the period of 1992-2001.8 In 2006, Kumar AS reported in-hospital mortality of 3.6\% for mitral valve repair.9 In 2012, Brown et al evaluated 40 year data of mitral valve replacement in children. Their rheumatic population consisted of $28 \%$ of patients. They reported 30 day mortality of $6 \%$. In 2014, Dillon et al reported a comparable mortality of $4.3 \%$ in RHD patients in Malaysia. The Australian RHD valve replacement study in 2015 found $3.1 \%$ mortality for RHD related valve replacements. 4

The main finding of the study is the identification of predictors of in hospital mortality. Age was one of the predictors and analysis ROC curve revealed a cut of value of 37.5 years above which mortality increased significantly. Above that cut off value, a twofold increase in mortality was seen [OR 2.05 (95\% CI 0.775.45)]. Increasing age has been associated with poorer outcome in previous studies.10 Previous studies have identified age above fifty as risk factor for operative mortality in mitral valve surgery. Our study has identified age as a risk factor for mortality in rheumatic valve replacement patients; however the age at which mortality increases is much lower for rheumatic population.

NYHA class was identified as a highly significant predictor of mortality in this study. Tribouilloy et al evaluated the impact of preoperative symptoms on survival after surgical correction of organic mitral regurgitation. They evaluated 478 patients, 199 in NYHA functional class I/II and 279 in class III/IV preoperatively with organic mitral regurgitation, operated between 1984 and 1991. Patients in class III/IV had higher operative mortality $(0.5 \%$ versus $5.4 \%, \mathrm{P}=0.003)$.

Our study revealed almost five-fold higher mortality for patients with left atrial thrombus (OR 4.96 (95\% CI 1.49-16.43); $\mathrm{p}=0.003$. Previously, left atrial thrombus itself has not been identified as a predictor for mortality in rheumatic patients. This is a novel finding of this study. It is a subject for further studies whether the increase in surgical mortality is due to the severity of the disease or due to unseen intraoperative thromboembolic events.

Systolic dysfunction of left ventricle and severity of tricuspid regurgitation are identified as predictors of outcome in previous studies; findings similar to ours. Patients who died (nonsurvivors) had increased $\mathrm{LV}$ dimensions (5.6 vs $4.9 \mathrm{~cm}$ ); low EF (50 vs $60 \%$ ); and severe TR (64 vs $41 \%$ ) preoperatively. LVEF measured by echocardiography has been identified as the most powerful predictor of long term survival. Predominant lesion in our study was regurgitation for both mitral $(n=327)$; and aortic $(\mathrm{n}=126)$ valves.

Isolated MVR with or without TV repair; DVR with or without TV repair did not affect the mortality. One patient had undergone MVR with concomitant CABG; and he survived the procedure. Majority of survivors had inotrope score of $<10$; as opposed to the score of $>10$ in non-survivors. Pump time and aortic clamp time was higher among non-survivors although it did not reach to a level of statistical significance. Reperfusion arrhythmias, intraoperative use of amiodarone, and requirement of epicardial pacing were similar among survivors and non-survivors; however duration of mechanical ventilation and length of ICU stay were significantly longer among non-survivors.

\section{Limitations}

The most important limiting factor is retrospective nature of the study. Another limitation of the study was inclusion of limited number of predicting variables. The basic difficulty in prediction of outcomes in patients undergoing cardiac surgery is the occurrence of wide range of complications. Unforeseen events may occur that influence the perioperative course. Furthermore, the diversity and individuality of biological response to anesthesia, cardiopulmonary bypass, and surgery may hinder the accuracy of prediction. An important predictor (preoperative and postoperative renal dysfunction) was excluded from analysis due to large number of missing values. Apart from that, logistic regression assumes a parametric distribution which is unstable for small numbers, e.g; a small number of re-exploration turned out to be significant in this study. Our study consists of only inhospital mortality and further studies with post-surgical follow up will demonstrate long term outcome predictors.

In conclusion, we identified age, NYHA class, severe TR, thrombus in left atrium, re-exploration for bleeding, decreasing LVEF, high inotrope score, longer duration of mechanical 
ventilation, and ICU stay as the independent predictors of inhospital mortality among patients undergoing mitral or double valve replacement for rheumatic heart disease.

Sources of funding: none

Acknowledgement: We acknowledge Dr Ashish Dhital, Dr Sharad Khakurel, Luna Maharjan, and Mahima Shrestha for their valuable help in data acquisition.

Conflicts of interest: The authors have nothing to disclose.

\section{References}

1. World Health Organization. Rheumatic fever and rheumatic heart disease: Report of a WHO expert consultation, Geneva, 20 October-1 November 2001.

2. Cruz DN, Antonelli M, Fumagalli R, Foltran F, Brienza N, Donati A, et al. Early use of polymixin B hemoperfusion in abdominal septic shock: the EUPHAS randomized controlled trial. JAMA 2009; 301 (23):2445-52.

3. Seckeler MD, Hoke TR. The worldwide epidemiology of acute rheumatic fever and rheumatic heart disease. Clin Epidemiol 2011;3:67-84.

4. Russell EA, Tran L, Baker RA, Bennetts JS, Brown A, Reid $\mathrm{CM}$, et al. A review of outcome following valve surgery for rheumatic heart disease in Australia. BMC Cardiovascular Disorders 2015;15:103. DOI: http://dx.doi.org/10.1186/ s12872-015-0094-1

5. Zuhlke L, Engel ME, Karthikeyan G, et al. Characteristics, complications, and gaps in evidence-based interventions in rheumatic heart disease: the Global Rheumatic Heart Disease Registry (the REMEDY study). Eur Heart J 2015;36:1115-22.

6. Diker E, Aydogdu S, Ozdemir M, Kural T, Polat K, Cehreli $\mathrm{S}$, et al. Prevalence and predictors of atrial fibrillation in rheumatic valvular heart disease. Am J Cardiol. 1996;77:968.

7. Zhang W, Okello E, Nyakoojo W, Lwabi P, Mondo CK. Proportion of patients in the Uganda rheumatic heart disease registry with advanced disease requiring urgent surgical interventions. Afri Health Sci 2015;15(4):1182-8. http://dx.doi.org/10.4314/ahs.v15i4.17.

8. Ho HT, Nguyen V, Phan K, Pham N. Mitral Valve Repair with Aortic Valve Replacement in Rheumatic Heart Disease. Asian Cardiovasc Thorac Ann 2004;12:341-5.

9. Kumar AS, Talwar S, Saxena A, Singh R, Velayoudam D. Results of mitral valve repair in rheumatic mitral regurgitation. Interact CardioVasc and Thorac Surg 2006;5:356-61. http://dx.doi.org/10.1510/ icvts.2005.121590

10. Galloway AC, Colvin SB, Baumann FG, Grossi EA, Ribakove GH, Harty S, et al. A Comparison of mitral valve reconstruction with mitral valve replacement: intermediate term results. Ann Thoruc Surg 1989;47:655-62.

11. Brown JW, Fiore AC, Ruzmetov M, Eltayeb O, Rodefeld MD, Turrentine MW. Evolution of Mitral Valve Replacement in Children: A 40-Year Experience. Ann Thorac Surg 2012;93:626-33.

12. Dillon J, Yakub MA, Kong PK, Ramli MF, Jaffar N, Gaffar IF. Comparative long-term results of mitral valve repair in adults with chronic rheumatic disease and degenerative disease: Is repair for "burnt-out" rheumatic disease still inferior to repair for degenerative disease in the current era? J Thorac Cardiovasc Surg 2014;149:771-9.

13. Mehta RH, Eagle KA, Coombs LP, Peterson ED, Edwards $\mathrm{FH}$, Pagani FD, et al. Influence of age on outcomes in patients undergoing mitral valve replacement. Ann Thorac Surg 2002;74:1459-67. http://dx.doi.org/10.1016/S00034975(02)03928-0

14. Tribouilloy CM, Enriquez-Sarano M, Schaff H V, Orszulak TA, Bailey KR, Tajik AJ, et al. Impact of preoperative symptoms on survival after surgical correction of organic mitral regurgitation: rationale for optimizing surgical indications. Circulation 1999;99:400-5. http://dx.doi. org/10.1161/01.CIR.99.3.400

15. Enriquez-Sarano M, Tajik AJ, Schaff HV, Orszulak TA, Bailey KR, Frye RL. Echocardiographic prediction of survival after surgical correction of organic mitral regurgitation. Circulation 1994;90(2):830-7.
Cite this article as: Apurba Sharma, et al. Predictors of in-hospital mortality following mitral or double valve replacement for RHD. Nepalese Heart Journal 2016;13(2): $19-24$. 